\title{
Volatile anesthetic for the control of posthypoxic refractory myoclonic status
}

\author{
Vivek Rayadurg, Radhakrishnan Muthuchellappan, Umamaheshwara Rao
}

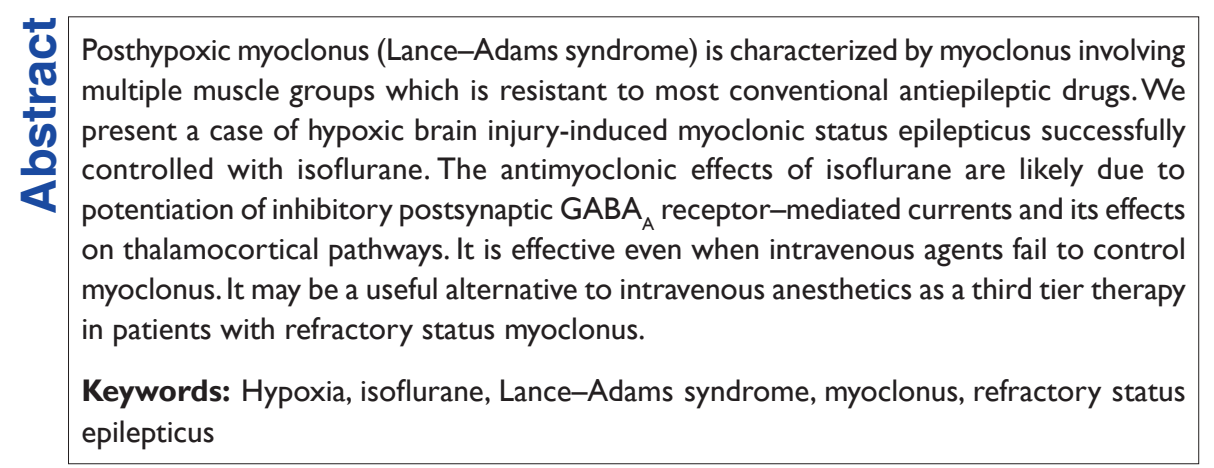

\begin{tabular}{|l|}
\hline Access this article online \\
\hline Website: www.jiccm.org \\
\hline DOI: 10.4103/0972-5229.188208 \\
\hline Quick Response Code: \\
\hline \\
\hline
\end{tabular}

\section{Introduction}

Posthypoxic myoclonus (Lance-Adams syndrome), resulting from hypoxia of the central nervous system, is characterized by action myoclonus, cerebellar ataxia, and mild intellectual deficit. Acute posthypoxic myoclonus can be divided into status myoclonus and multifocal myoclonus. Wijdicks et al. ${ }^{[1]}$ defined status myoclonus as "spontaneous or sound-sensitive, repetitive, irregular brief jerks in both face and limb present during most of the day after a cardiorespiratory arrest." The most dreaded aspect of this syndrome is its known resistance to conventional anticonvulsants. ${ }^{[2]}$ However, it is a very rare condition, with not many cases in literature.

We present an adult male patient who suffered hypoxic brain injury, following which he developed severe status myoclonus unresponsive to standard anticonvulsant polytherapy. He had significant improvement after administering isoflurane, an inhalational anesthetic.

From:

Department of Neuroanaesthesia, National Institute of Mental Health and Neurosciences, Bengaluru, Karnataka, India

\section{Correspondence:}

Dr. Vivek Rayadurg, Department of Neuroanaesthesia, National Institute of Mental Health and Neurosciences, Bengaluru - 560 029, Karnataka, India.

E-mail: rayadurg.vivek@gmail.com

\section{Case Report}

A 60-year-old male, known case of myasthenia gravis, presented with symptomatic recurrence. Treatment was initiated with plasma exchange and intramuscular neostigmine, resulting in considerable clinical improvement. Endotracheal intubation was not planned in view of normal arterial blood gas values and no signs of respiratory distress.

On day 5 of hospital stay, in the Intensive Care Unit (ICU), the patient suddenly complained of difficulty in breathing. This was followed by bradycardia, arterial desaturation, and loss of consciousness. The patient was immediately resuscitated, intubated, and mechanical ventilation started. The lowest heart rate recorded was $30 / \mathrm{min}$. There was no episode of asystole.

This is an open access article distributed under the terms of the Creative Commons Attribution-NonCommercial-ShareAlike 3.0 License, which allows others to remix, tweak, and build upon the work non-commercially, as long as the author is credited and the new creations are licensed under the identical terms.

For reprints contact: reprints@ medknow.com

How to cite this article: Rayadurg V, Muthuchellappan R, Rao U. Volatile anesthetic for the control of posthypoxic refractory myoclonic status. Indian J Crit Care Med 2016;20:485-8 
However, after the event, the patient developed continuous, spontaneous, high amplitude, and generalized myoclonic jerks. The jerks were exaggerated with stimuli such as touch, call, tracheal suctioning, and physiotherapy. To control these myoclonic jerks, the patient was sequentially put on phenytoin $\left(100 \mathrm{mg} 8^{\text {th }}\right.$ hourly), levetiracetam $\left(1 \mathrm{~g} 8^{\text {th }}\right.$ hourly), valproate $\left(1 \mathrm{~g} 12^{\text {th }}\right.$ hourly), piracetam ( $3 \mathrm{~g} 8^{\text {th }}$ hourly), lacosamide (400 $\mathrm{mg}$ $12^{\text {th }}$ hourly), and clonazepam (5 mg/day) over $48 \mathrm{~h}$. Owing to the continuous myoclonus, the neurological status of the patient could not be assessed at any time during this period. Bedside electroencephalography (EEG) in the ICU was not feasible because of persistent myoclonic jerks. As the myoclonus was still not controlled, thiopentone $(100 \mathrm{mg} / \mathrm{h})$ and midazolam $(5 \mathrm{mg} / \mathrm{h})$ infusions were also started, but myoclonus was still continuously present. A magnetic resonance imaging (MRI) of the brain was obtained $72 \mathrm{~h}$ after the onset of status myoclonus, which surprisingly revealed no structural changes suggestive of hypoxia [Figure 1].

Interestingly, it was observed that isoflurane, which was administered during MRI at a concentration of $0.6 \%$ in $50 \%$ oxygen in air, completely abolished the myoclonic jerks for the duration that it was administered. Hence, it was decided to administer isoflurane in the ICU to control the myoclonus. Isoflurane was administered using an anesthesia machine (Fabius, Drager, Germany) with air and oxygen as carrier gases. The jerks completely disappeared at a minimum alveolar concentration (MAC) of 0.4 (Ultraview, Spacelabs, USA). Isoflurane concentration was titrated, and it was found that the jerks were suppressed at a MAC of 0.3-0.4. The therapy was continued for $48 \mathrm{~h}$ empirically to break the status. All other anticonvulsants, except midazolam and thiopentone infusions, were continued in their previous dosages. At the end of $48 \mathrm{~h}$, isoflurane was stopped to observe for myoclonus. Fifteen minutes after cessation of anesthetic administration, patient regained consciousness, followed commands, and there was a significant decrease in the severity of myoclonus. The jerks were absent at rest and appeared only when the patient tried to perform some action. As the patient continued to improve, most of his antiepileptics were
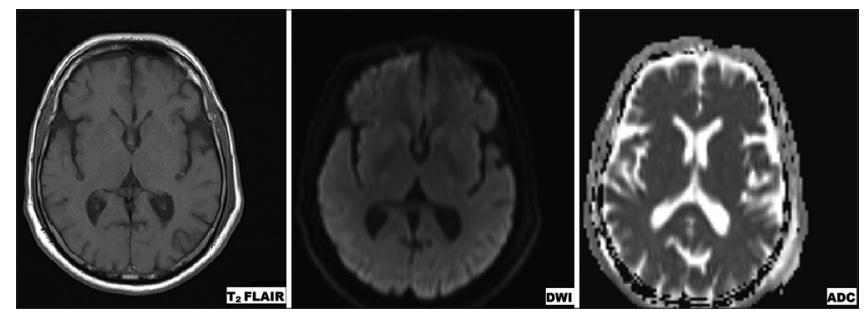

Figure I: Magnetic resonance imaging brain showing no structural changes gradually tapered and stopped. At the end of 1 month of hospital stay, he was only on oral lacosamide 400 $\mathrm{mg}$ /day and oral clonazepam $5 \mathrm{mg} /$ day for control of myoclonus. He was transferred to a rehabilitation center with a Glasgow coma scale score of $\mathrm{E}_{4} \mathrm{M}_{6} \mathrm{~V}_{\text {Tracheostomy' }}$; minimal jerks triggered by movement and none at rest.

\section{Discussion}

Posthypoxic myoclonus is a subcortical phenomenon involving many muscle groups and is sensitive to external stimuli such as sounds. Stimulus-sensitive myoclonus is extremely difficult to treat and often interferes with the nursing care of these patients. It is a relatively rare syndrome and was first described by Lance and Adams in 1963. ${ }^{[2]}$ Here, neuroimaging tests such as computed tomography or MRI of the brain are usually unremarkable. Lacunar infarcts, loss of gray-white matter distinction and selective neuronal injuries in the gray deep nuclei may be seen due to diffuse neuronal injury, but usually, it is not specific of hypoxic myoclonus. EEG may show evidence of short duration spike and polyspike discharges or may be completely normal. We could not do EEG because of persistent myoclonus which is likely to produce more movementinduced artefacts.

Status myoclonus with loss of consciousness following hypoxic injury is considered a bad prognostic sign. As it was persistent in our patient, MRI was planned to assess the severity of hypoxic brain damage. Surprisingly, MRI did not show any structural lesions, and hence we decided to use isoflurane to treat the myoclonus aggressively as the last treatment option.

Posthypoxic myoclonus is notorious for being resistant to conventional anticonvulsant agents. Owing to lack of literature, no standard treatment guidelines exist, and treatment is based on "trial-and-error" method. Standard anticonvulsants such as phenytoin and phenobarbital have not been found useful. ${ }^{[3]}$ Favorable response has been reported with clonazepam, valproic acid ${ }^{[4]}$ piracetam ${ }^{[5]}$ and levetiracetam, ${ }^{[6]}$ zonisamide and lacosamide. ${ }^{[7]}$ However, very high doses of piracetam (20-45 g/day) or levetiracetam (3000-3500 mg/day) are required in the treatment of myoclonus which is not very practical. But in our patient, none of the above-mentioned medications were able to control the status myoclonus.

GABAergic agents lose their efficacy in prolonged seizures, due to excess glutamate release when seizure activity lasts longer than $1 \mathrm{~h}$, resulting in an altered 
balance of excitation versus inhibition. ${ }^{[8]}$ In addition, the benzodiazepine receptors lose their affinity for their ligands, reducing their potency. This might be the reason why thiopentone and midazolam infusions failed to control the myoclonus in our patient. Isoflurane has been found to abolish seizures within minutes in such cases. $^{[9,10]}$

Although the mechanism of action of isoflurane is not well understood, the antimyoclonic effects of isoflurane are likely due to potentiation of inhibitory postsynaptic $\mathrm{GABA}_{\mathrm{A}}$ receptor-mediated currents and its effects on thalamocortical pathways. ${ }^{[11]}$ Isoflurane produces dose-dependent changes in the EEG. With increasing concentrations, there is a gradual decrease in voltage with increasing periods of electrical silence. The pharmacological properties of isoflurane make it an effective and easily titratable agent in suppressing seizures. Other advantages, including rapid onset of action and elimination and the reduced potential for toxic effects on organs owing to its minimal metabolism, make it an ideal choice of therapy. Isoflurane can cause EEG spiking and myoclonus, but it has not been associated with frank epileptoid activity. Therefore, epileptogenesis does not appear to be a clinical concern with isoflurane. ${ }^{[12]}$

While Kofke et al..$^{[9]}$ administered isoflurane for a period ranging from 1 to $55 \mathrm{~h}$ for 11 patients with refractory generalized clonic-tonic seizures, Mirsattari et al. ${ }^{[10]}$ administered isoflurane for 2-26 days (and supplemental desflurane for 19 days in one patient) in 7 patients. In both these reports, the anesthetic concentration was titrated based on EEG burst suppression. Although it is recommended to achieve EEG-guided burst suppression for adequate control of seizures, in our patient, we titrated isoflurane dose (MAC) to control the patient's clinical jerks only and found that only low concentrations of isoflurane was required to achieve this end-point. Furthermore, we discontinued isoflurane administration after $48 \mathrm{~h}$, while continuing the rest of the anticonvulsant medications. This helped us to avoid hypotension and the need for vasopressors, which are invariably associated with prolonged administration of high concentrations of volatile anesthetics. In comparison, Kofke et al..$^{[9]}$ report increased incidence of hypotension and vasopressor use in most patients and increased urinary fluoride concentrations in one patient and Mirsattari et al..$^{[10]}$ report adverse effects such as vasopressors/inotropes use, atelectasis, infections, paralytic ileus, cardiac arrhythmias, and mild renal dysfunction. Moreover, isoflurane being a volatile agent and not being metabolized in the body, there was no risk of accumulation and prolonged effect when administered only for $48 \mathrm{~h}$. The route of elimination being through the lungs, our patient was awake within 15 min of its termination. This is in contrast to intravenous agents like thiopentone which get accumulated after prolonged administration resulting in delayed awakening.

However, owing to technical and logistical difficulties, isoflurane cannot be used routinely in ICUs as an antiepileptic agent. The need for an anesthesia machine and specialized vaporisers to deliver the anesthetic agents and the lack of familiarity of ICU personnel with both the machine and the agents make it difficult for routine use. Pollution of the ICU atmosphere by the isoflurane-containing exhaled gasses owing to lack of a scavenging system is another hindrant. However, with the advent of newer devices such as AnaConDa ${ }^{\circledR}$ (Sedana Medical, Ireland), administration of volatile anesthetics in ICUs has become simpler.

It should be remembered that the goal of management in any case of refractory status epilepticus is to achieve burst suppression on EEG. The possible limitation in our case is that EEG was not monitored and isoflurane was titrated to suppress clinical myoclonus only. Whether this resulted in suppression of electrical seizure activity in the brain is unknown. However, because we continued all other antiepileptics throughout the isoflurane administration period, and because the patient had significantly improved outcome after termination of isoflurane, we speculate that the seizure activity would have decreased significantly, even if not completely abolished. As such, whether the same success is reproducible in other patients cannot be commented on.

\section{Conclusion}

Isoflurane is an effective, rapidly titratable antimyoclonic agent which may serve as a useful alternative when intravenous anesthetics fail in patients with refractory status myoclonus. Although isoflurane does not reverse the underlying etiology, it may rapidly control the symptoms of refractory myoclonus.

\section{Financial support and sponsorship}

Nil.

\section{Conflicts of interest}

There are no conflicts of interest.

\section{References}

1. Wijdicks EF, Parisi JE, Sharbrough FW. Prognostic value of myoclonus status in comatose survivors of cardiac arrest. Ann Neurol 1994;35:239-43. 
2. Lance JW, Adams RD. The syndrome of intention or action myoclonus as a sequel to hypoxic encephalopathy. Brain 1963;86:111-36.

3. Polesin A, Stern M. Post-anoxic myoclonus: A case presentation and review of management in the rehabilitation setting. Brain Inj 2006;20:213-7.

4. Rollinson RD, Gilligan BS. Postanoxic action myoclonus (Lance-Adams syndrome) responding to valproate. Arch Neurol 1979;36:44-5.

5. Terwinghe G, Daumerie J, Nicaise C, Rosillon O. Therapeutic effect of piracetam in a case of posthypoxic action myoclonus (author's transl). Acta Neurol Belg 1978;78:30-6.

6. Krauss GL, Bergin A, Kramer RE, Cho YW, Reich SG. Suppression of post-hypoxic and post-encephalitic myoclonus with levetiracetam. Neurology 2001;56:411-2.

7. Galldiks N, Timmermann L, Fink GR, Burghaus L. Posthypoxic myoclonus (Lance-Adams syndrome) treated with lacosamide. Clin
Neuropharmacol 2010;33:216-7.

8. Ries CR, Puil E. Mechanism of anesthesia revealed by shunting actions of isoflurane on thalamocortical neurons. J Neurophysiol 1999;81:1795-801.

9. Kofke WA, Young RS, Davis P, Woelfel SK, Gray L, Johnson D, et al. Isoflurane for refractory status epilepticus: A clinical series. Anesthesiology 1989;71:653-9.

10. Mirsattari SM, Sharpe MD, Young GB. Treatment of refractory status epilepticus with inhalational anesthetic agents isoflurane and desflurane. Arch Neurol 2004;61:1254-9.

11. Langmoen IA, Hegstad E, Berg-Johnsen J. An experimental study of the effect of isoflurane on epileptiform bursts. Epilepsy Res 1992;11:153-7.

12. Patel PM, Drummond JC, Lemkuil BP. Cerebral physiology and the effects of anaesthetic drugs. In: Miller RD, editor. Miller's Anaesthesia. $8^{\text {th }}$ ed. Philadelphia: Elsevier; 2015. p. 409. 